\title{
¿Qué es transparencia?
}

\section{Rafael RAMÍREZ VILLAESCUSA ${ }^{1}$ \\ SUMARIO: I. Introducción II. La dimensión jurídica de la transparencia III. Conclusiones IV. Bibliografía}

\begin{abstract}
Resumen
El reciente proceso de consolidación democrática experimentado por México en la última década ha estado acompañado de una serie de políticas públicas encaminadas a fortalecer la participación ciudadana dentro de la toma de decisiones, así como la rendición de cuentas gubernamental. Una de esas acciones consistió en la promulgación, durante el sexenio del Presidente Fox, de la Ley Federal de Transparencia y Acceso a la Información Pública Gubernamental. Lo anterior, además, se inscribió en el contexto de un movimiento global a favor del derecho a saber, impulsado por diversas organizaciones internacionales. Parece ser que la transparencia llegó para quedarse, lo cual no significa que la tarea de consolidación y desarrollo democrático haya terminado. El presente artículo forma parte de una serie de entregas que pretenden aportar una visión interdisciplinaria del concepto. Corresponde esta primera colaboración a un análisis descriptivo de la transparencia a partir de su dimensión jurídica.
\end{abstract}

\begin{abstract}
The recent democratic development process in Mexico has been accompanied of several policies to enhance civic participation and to strength government accountability. One of those actions was the enactment of the Federal Law of Governmental Transparency and Access of Information, during president Fox administration. Those actions took part in a context of international promotion of right to know acts and policies. It's seems that transparency just arrived to stay for a long time, but that doesn't mean that our democratic consolidation has reach an end. The present essay is part of a set of articles that seek to promote an interdisciplinary approach to transparency. Particularly, the present article corresponds to a descriptive analysis of transparency from a legal perspective.
\end{abstract}

Palabras clave: Transparencia, Acceso a la Información, Rendición de Cuentas Keywords: Transparency, Access of information, Accountability 


\section{Introducción}

La transparencia es un concepto difícil de definir pero fácil de entender. Todos esperamos que nuestras autoridades realicen su tarea de la mejor forma posible. Para ello requerimos que el trabajo efectuado dentro del gobierno se haga de cara a la sociedad. Un gobierno que actúa bajo las sombras es un gobierno con reticencia a la rendición de cuentas. No es de extrañar, por tanto, que allá donde los servidores públicos realizan su trabajo amparados en la secrecía, la sociedad enfrente importantes déficits democráticos. ${ }^{2}$

La dificultad para hallar una definición unívoca de la cuestión radica -a nuestro entender- en el hecho de que el vocablo transparencia se encuentra íntimamente relacionado con otras categorías jurídicas y políticas tales como acceso a la información y rendición de cuentas. Al tenor de lo anterior, Guerrero ha señalado que: "la transparencia es un asunto interdisciplinario que tiene resortes en la economía, en el derecho, en la ciencia política, en la moral y que tiene también consecuencias que se mueven en varios ámbitos de la vida social" (2005, 26). Por tanto, cualquier intento por tener una visión más o menos comprehensiva de la temática en cuestión, nos conduce a la necesaria adopción de un enfoque multidisciplinario. Creemos, siguiendo tales ideas, que son tres las dimensiones que pueden resultar esenciales para entender a la transparencia: una primera dimensión jurídica, una segunda dimensión económica y una tercera dimensión política. El orden de las mismas, sin embargo, no supone ningún tipo de primacía.

Atendiendo a lo anterior, la presente forma parte de una serie de colaboraciones cuyo objeto primordial consistirá en abordar al concepto de transparencia a partir de cada una de estas dimensiones. En este primer trabajo abordaremos la dimensión jurídica del citado concepto. Lo anterior es relevante, ya que consideramos que esta dimensión se corresponde muy bien con lo que 
más adelante -en otras de nuestras colaboraciones- habremos de llamar políticas de transparencia de primera generación.

\section{La dimensión jurídica de la transparencia}

Desde el punto de vista del derecho, el de transparencia es un concepto que no puede ser desligado de otros tantos tales como derecho a la información, acceso a la información e incluso el de rendición de cuentas. Lo anterior no resulta ocioso, sobre todo si atendemos la importancia que desde el punto de vista jurídico reviste el correcto uso de los conceptos. El presente apartado busca desentrañar la naturaleza jurídica de la transparencia como un concepto estrechamente ligado al derecho a la información. En este sentido partiremos de la categoría más general -derecho a la información- e iremos avanzando hasta llegar a la de transparencia. Entre las preguntas a las que procuraremos dar respuesta destacan las siguientes: ¿Qué es el derecho a la información? ¿Qué estatuto legal le corresponde? ¿Cuál es el objeto del derecho a la información? ¿Cuál o cuáles son los bienes jurídicamente tutelados? ¿Quiénes son los sujetos de tal derecho? ¿Qué relación guarda el derecho a la información con la transparencia? ¿Puede existir un derecho a la información sin transparencia o viceversa? Comenzaremos por definir el que creemos es el más amplio de los conceptos relacionados con la transparencia: el derecho a la información.

\section{A) Derecho a la información y acceso a la información pública}

Jorge Carpizo parte de lo dispuesto por el artículo 19 de la Declaración Universal de los Derechos del Hombre $(\mathrm{DUDH})^{3}$ para definir al derecho a la información como "la garantía fundamental que toda persona posee a: atraerse información, a informar y a ser informada". A partir de dicha definición se desprenden los elementos más importantes de dicha garantía: 
a) Un derecho a atraerse información que comprende a su vez distintas facultades: 1) Acceso a los archivos, registros y documentos públicos y 2) La decisión de que medio se lee, se escucha o se contempla;

b) Un derecho a informar que comprende a su vez distintas libertades: 1) Libertad de expresión y de imprenta y 2) Libertad de constitución de sociedades y empresas informativas;

c) Un derecho a ser informado que a su vez comprende las siguientes facultades: 1) Recibir información veraz y oportuna, 2) Dicha información debe ser completa, es decir, el derecho a enterarse de todas las noticias y 3) Con carácter universal, es decir, que la información sea para todas las personas sin exclusión alguna (2003, 28-29).

Atendiendo a lo anterior, Nogueira señala que: "el derecho a la información constituye así, un complejo de derechos que dicen tener relación tanto con el sujeto que informa (informador) como con quién recibe dicha información" (2000, 3-4). Lo anterior explica en buena medida el ya famoso criterio de la Suprema Corte de Justicia de Colombia que califica al derecho de la información como un derecho de doble vía, es decir, que otorga libertades al emisor de la información pero que a la vez establece un derecho a la veracidad, a la oportunidad y a la universalidad en la misma a favor del receptor. ${ }^{4}$

Para algunos, entre ellos López Ayllón $(2000,163){ }^{5}$ el derecho a la información es sinónimo de las libertades de expresión e información. Lo anterior es relevante tratándose del acceso a la información pública ya que como afirma Mendel: "la posibilidad de acceso a la información en poder del gobierno es un derecho protegido internacionalmente, puesto que se configura dentro del derecho a la libertad de expresión, que incluye las prerrogativas de buscar y recibir información" $(2006,7)$. De esta forma el derecho de acceso a la información forma parte de una libertad más amplia como lo es la de expresión -misma que lo contiene más no lo agota- y esta a su vez está contenida dentro del derecho, aún más genérico, a la información. Sin embargo, la naturaleza del derecho de acceso a la información en manos del gobierno resulta un tanto ambigua ya que no existe 
un consenso generalizado en asumirlo como un derecho humano. En algunos países está claro que se trata de un derecho público subjetivo contemplado en la legislación -a través de las llamadas leyes de acceso a la información- en otros tantos constituye un verdadero derecho fundamental al estar positivizado en las respectivas constituciones. ${ }^{6}$ Para Catala i Bas el derecho de acceso a la información es un derecho fundamental en la medida en que "la libertad de expresión e información supone la posibilidad de acceder libremente a la información...". (2001, 65) La postura del acceso a la información como un verdadero derecho humano tiene, por otro lado, un sólido sustento jurisprudencial por parte de la Corte Interamericana de Derechos Humanos en su sentencia Claude Reyes y otros vs Chile de 19 de septiembre de $2006 .^{7}$

No obstante lo anterior y por extraño que parezca, Europa ha sido una de las regiones más reticentes a reconocer el carácter del acceso a la información como derecho humano. Al respecto, Mendel señala que a pesar de la existencia de una resolución del Comité de Ministros del Consejo de Europa, en donde se reconoce la importancia del acceso a la información y a través de la cual se insta a los Estados miembros para adoptar legislación que la garantice, ha sido la Corte Europea de Derechos Humanos (CEDH) la que se "ha negado sistemáticamente a reconocer el derecho de acceso a la información como una parte del derecho de la libertad de expresión y lo ha catalogado como parte del derecho a la vida familiar y a la privacidad" (2006, 8-9). No obstante lo anterior se advierte una progresiva tendencia por parte de la CEDH en tal sentido. Al respecto resulta interesante la sentencia Társaság A Szabadságjogokért v. Hungary de 14 de abril de $2009^{18}$, misma que supone un avance toda vez que adopta una interpretación más amplia de la libertad para recibir informaciones. Si bien la Corte Europea aún no reconoce al acceso a la información como derecho humano, sí lo hace como un derecho esencial de la prensa y en general de todas las organizaciones que actúan como "perros guardianes" de la sociedad para posibilitar el correcto desempeño de su función de informar. La distinción hecha sobre un mismo derecho -el de acceso a 
la información pública y su estatus legal- no resulta pueril, sobre todo desde el punto de vista de la eficacia en su aplicación. ${ }^{9}$

Más allá del estatuto legal que al acceso a la información le corresponda, lo cierto es que las diversas ideas hasta ahora manifestadas coinciden con Villanueva cuando señala que "el derecho de acceso a la información es, en suma, uno de los derechos subsidiarios del derecho a la información en sentido amplio..." (2003, 24). Lo anterior no significa otra cosa más que la idea, ya apuntada, de que un efectivo ejercicio de la libertad de información supone también la posibilidad de que todo individuo acceda a la información que se encuentra en manos del poder público. En este sentido y siguiendo a Urías, el derecho a la información no se limita tan solo a la existencia de una libertad sino que adquiere también un componente de derecho prestacional al surgir una obligación, por parte del Estado, de facilitar la información que obra en su poder $(2003,77)$.

\section{B) Sujetos, objeto y bien jurídico tutelado del derecho de acceso a la información}

Como cualquier derecho, el acceso a la información comporta la existencia de sujetos, objeto y bienes jurídicos tutelados. En el primero de los casos allá donde el derecho de acceso a la información se encuentra positivizado ya como derecho fundamental o bien como derecho ordinario, la tendencia creciente es a la universalización del sujeto activo -titular del derecho- ya sea a través de la facultad concedida a cualquier persona para acceder a los documentos de carácter público o bien, en un supuesto más restrictivo, a la concesión de dicha facultad a los ciudadanos. Sin embargo, la postura mantenida por la Corte Europea legitima como sujetos de tal derecho solo a los integrantes de las organizaciones periodísticas o afines, en tanto actúan en el ejercicio de su función profesional. No obstante lo anterior, el acceso a la información pública ha tenido en Europa otra vía distinta para su desarrollo: el derecho administrativo. De esta forma y por mencionar tan solo el caso español, el artículo 105.b de la 
Constitución Política de ese país señala que la "ley regulará el acceso a los ciudadanos a los archivos y registros administrativos". Dicha regulación la podemos encontrar dentro de la Ley de régimen jurídico de las administraciones públicas y del procedimiento administrativo común de 26 de noviembre de 1992 (modificada por la Ley 4/1999 de 13 de enero) misma que en su artículo 37.1 confiere a todos los ciudadanos el "derecho a acceder a los registros y a los documentos que, formando parte de un expediente, obren en los archivos administrativos, cualquiera que sea la forma de expresión, gráfica, sonora o en imagen o el tipo de soporte material en que figuren, siempre que tales expedientes correspondan a procedimientos determinados". Sin embargo, tal derecho no ampara lo relacionado con la documentación en posesión del Poder Legislativo, el Poder Judicial y otros órganos autónomos del Estado. Por lo que respecta al sujeto pasivo -titular de la obligación- la tendencia internacional apunta hacia todo órgano del Estado y en algunos casos hasta particulares que reciben recursos públicos o desempeñan alguna función delegada por la administración.

Por lo que respecta al objeto de tal derecho no existe mucho sobre lo que abundar. A reserva de estarnos a lo dispuesto en la legislación de cada país, el objeto suele ser toda clase de documentos contenidos en archivos y registros públicos con independencia del soporte en el que se encuentren. La cuestión del bien jurídico tutelado es poco más compleja. Siguiendo el criterio de la Corte Europea podríamos concluir que el bien jurídico que se busca tutelar es la formación de una opinión pública informada. Esta sería también, en alguna forma, la postura sostenida por quienes ven al derecho de acceso a la información como parte indisoluble de la libertad de información. Al respecto Nogueira señala: "la información es un bien público que debe ser protegido por la democracia, ya que el pluralismo informativo y la recepción de las diversas informaciones de relevancia pública por las personas, es de gran trascendencia para la recepción de los asuntos públicos y de gobierno por la ciudadanía". Al tenor de lo anterior continúa el citado autor, el Estado y sus órganos deben "garantizar efectivamente la libre circulación de la información e impedir que ella sea obstaculizada por terceros, todo lo cual permite el desarrollo social" $(2000,29)$. Esta postura ubica al 
acceso a la información como un derecho esencial para la vida democrática, el mejor ejercicio de los derechos políticos y la capacidad de los ciudadanos de llamar a rendición de cuentas a sus gobernantes.

Sin embargo, la postura de otros autores como Ernesto Villanueva no solo complementa a la anterior sino que la amplía. Es decir, el bien jurídico tutelado a través del acceso a la información no es ya solo la existencia de una opinión pública informada sino también la calidad de vida de las personas lato senso. En este sentido, el derecho de acceso a la información "se convierte en un requisito sine qua non para el ejercicio de otros derechos", muchos de los cuales precisan de información veraz y oportuna para no pasar a ser letra muerta $(2003,29-34) .{ }^{10}$ ¡Qué duda cabe que la información juega un papel fundamental para la toma colectiva o individual de decisiones! De esta forma, un ciudadano bien informado se sitúa en una mejor posición para tomar decisiones relevantes para su bienestar y participar de una mejor manera de las políticas públicas de su gobierno. ${ }^{11}$ Para Villanueva el logro de tal objetivo requiere del cumplimiento de diversas condiciones: entidades públicas que operen de manera transparente, rendición de cuentas ante la sociedad y máxima publicidad de los actos públicos (2003, 29-34). Con esto podemos finalmente introducir el concepto de transparencia dentro de nuestro planteamiento.

\section{C) Transparencia y máxima publicidad}

Contrario a lo que pudiera pensarse la transparencia no es un concepto nuevo dentro del contexto jurídico. Sucede que transparencia es un término de nuevo cuño para expresar un principio algo añejo como el de publicidad en los actos del Estado y en particular de la administración. Tal y como sostienen Caballero, Díaz y Villanueva, se trata de una institución de "vieja data, pero de reciente eficacia normativa como mecanismo de control de los actos de los gobernantes por los gobernados". En este sentido y siguiendo a los citados autores, la transparencia significaría "el deber de los mandatarios o gobernantes para realizar como regla general sus actuaciones de manera pública como un mecanismo de control del 
poder y de legitimidad democrática de las instituciones públicas" (2006, 12). La transparencia o principio de publicidad tiene, además, aristocráticos antecedentes filosóficos en las obras de Kant (1724-1802) y Bentham (1748-1832). El primero vinculó la transparencia a la moral a través de una máxima: "Todas las acciones que afectan el derecho de otros seres humanos son injustas si los principios que las guían no pueden soportar ser publicados" (Guerrero, 2008: 16). En tanto Bentham identificó cuatro beneficios derivados de la transparencia, que hoy en día siguen marcando el camino en la discusión y estudio de nuestro tema. Dichos beneficios pueden ser resumidos de la siguiente forma: 1) Disuade conductas oportunistas en los servidores públicos, 2) Genera y fortalece vínculos de confianza entre ciudadanos y autoridades, 3) Genera información relevante para el mercado electoral, 4) Contribuye a la retroalimentación gobierno-sociedad (Guerrero, 2008: 17-18).

¿Puede existir transparencia sin derecho a la información? ¿Puede existir derecho a la información sin transparencia? Para responder a tales cuestionamientos hemos de plantear, lo que a nuestro juicio, son dos manifestaciones del principio de publicidad de los actos del Estado: la primera -de carácter pasivo- se correspondería al acceso a la información propiamente dicho, en la medida en que los ciudadanos ejercen su derecho a informase a través de las solicitudes de información realizadas ante los órganos del gobierno. La segunda -de carácter activo- correspondería a aquellos supuestos en los que, sin mediar instancia de parte, el gobierno hace del conocimiento público información que considera relevante para el correcto ejercicio de otros derechos y abre canales de participación ciudadana en los procesos para la toma de decisiones (Troncoso, 2008: 25). Por tanto, la transparencia en su sentido más amplio (vertiente activa) presupone el acceso a la información. Así, un Estado transparente lo puede ser con independencia de la existencia o no de una ley pro acceso a la información. Sin embargo, la mera existencia de una ley de acceso, no supone necesariamente la existencia de un estado verdaderamente transparente.

De lo apuntado hasta ahora podemos sostener que la transparencia no puede ser considerada ni derecho, ni libertad. En el primero de los casos ya que nadie 
puede ejercer un derecho subjetivo a la transparencia. En el segundo ya que la transparencia implica una obligación positiva por parte del Estado, obligación que comporta el acceso a la información pública pero que no se agota en ello. ${ }^{12}$ Así, podríamos concluir que la transparencia es un principio de derecho público caracterizado por la máxima publicidad en los actos del Estado. ${ }^{13} \mathrm{El}$ acceso a la información sería una manifestación de un Estado transparente pero no la única. Si bien es cierto que la transparencia o principio de publicidad tiene origen en el derecho administrativo, existe una clara tendencia a su progresiva ampliación y hoy, en múltiples democracias, se extiende a otros ámbitos del Estado tales como el poder legislativo, los órganos constitucionales autónomos y por supuesto, el Poder Judicial.

\section{Conclusiones}

El presente artículo, primera parte de una serie de entregas, se ha propuesto desarrollar un análisis descriptivo de la transparencia desde su dimensión jurídica. Desde el punto de vista del derecho, la transparencia no puede ser desligada de conceptos como el de acceso a la información o el de publicidad en los actos del Estado. Si bien el acceso a la información pública no ha encontrado una aceptación universal como derecho humano, gran parte de las modernas constituciones lo catalogan como derecho fundamental. Solamente a través del reconocimiento al derecho de acceso a la información pública se logra hacer efectivo el derecho humano a la información, entendido como la garantía que todos los individuos poseen para atraerse información, informar y ser informados. La tendencia cada vez más creciente apunta hacia la universalización del sujeto activo de tal derecho, en tanto que el objeto del mismo -la información pública- puede ser definido como toda clase de documentos, en cualquier tipo de soporte, que se encuentre en poder de los órganos del Estado. Existen diversas posturas en torno al bien jurídico tutelado. Quienes sostienen que el derecho de acceso a la información pública es un derecho subsidiario a la libertad de información, defienden la idea de una opinión pública informada como bien jurídico 
a tutelar. Para otros, que conciben el acceso a la información pública como un derecho que posibilita el efectivo ejercicio de otros tantos, el bien jurídico tutelado es más amplio y se engloba en la preservación del bienestar general.

La transparencia es un principio general de derecho público estrechamente ligado al derecho de acceso a la información aunque con una naturaleza distinta. Es un principio que parte de una aristocrática tradición filosófica pero que ha ido evolucionando a lo largo del tiempo hasta adquirir su actual carácter. El principio de transparencia lo podríamos encontrar en dos manifestaciones de carácter complementario. Una primera manifestación -que llamamos pasiva- se correspondería con la posibilidad de que los ciudadanos accedan -sin obstáculo- a todas las actuaciones realizadas por parte de los órganos gubernamentales. Esta manifestación se correspondería con el acceso a la información pública propiamente dicho. La segunda manifestación -que llamamos activacorrespondería a aquellos supuestos donde, sin mediar instancia de parte, los órganos del Estado dan a conocer información que puede ser relevante para el logro del bienestar general o abren canales de participación ciudadana que posibilitan un mejor ejercicio de la rendición de cuentas o un funcionamiento óptimo del Estado y sus órganos, como proveedores de servicios públicos. La transparencia en su vertiente más activa recogería en su seno al acceso a la información pero no se agotaría en ello. En este orden de ideas, la transparencia sería definida como el principio en la actuación del Estado a través del cual los órganos del gobierno se comprometen a ejercer sus funciones con responsabilidad social, rendición de cuentas y máxima publicidad, procurando generar fórmulas de participación social en los procesos de deliberación pública y formación de políticas. 